\title{
Sniffing around oxytocin: review and meta-analyses of trials in healthy and clinical groups with implications for pharmacotherapy
}

\author{
MJ Bakermans-Kranenburg ${ }^{1,2}$ and MH van IJzendoorn ${ }^{1,2}$
}

The popularity of oxytocin (OT) has grown exponentially during the past decade, and so has the number of OT trials in healthy and clinical groups. We take stock of the evidence from these studies to explore potentials and limitations of pharmacotherapeutic applications. In healthy participants, intranasally administered OT leads to better emotion recognition and more trust in conspecifics, but the effects appear to be moderated by context (perceived threat of the 'out-group'), personality and childhood experiences. In individuals with untoward childhood experiences, positive behavioral or neurobiological effects seem lowered or absent. In 19 clinical trials, covering autism, social anxiety, postnatal depression, obsessive-compulsive problems, schizophrenia, borderline personality disorder and post-traumatic stress, the effects of OT administration were tested, with doses ranging from $15 \mathrm{IU}$ to more than $7000 \mathrm{IU}$. The combined effect size was $d=0.32(N=304$; $95 \%$ confidence interval (Cl): $0.18-0.47 ; \boldsymbol{P}<0.01$ ). However, of all disorders, only studies on autism spectrum disorder showed a significant combined effect size $(d=0.57 ; N=68 ; 95 \% \mathrm{Cl}$ : $0.15-0.99 ; P<0.01)$. We hypothesize that for some of the other disorders, etiological factors rooted in negative childhood experiences may also have a role in the diminished effectiveness of treatment with OT.

Translational Psychiatry (2013) 3, e258; doi:10.1038/tp.2013.34; published online 21 May 2013

\section{Introduction}

On the internet oxytocin (OT) is the most popular nonapeptide, with more than 5.7 million hits by the end of 2012, and its popularity has been growing exponentially during the past 10 years. OT is labeled the 'love hormone' and widely advertised as a wonder drug to enhance the individual's social skills on the job and at home, and to cure or alleviate more serious illnesses such as depression, post-traumatic stress, autism and other psychiatric syndromes. The number of psychopharmacological studies on OT in non-clinical groups has increased rapidly. After the initial excitement about positive effects on trust, it soon became clear that OT might be anxiolytic and facilitate prosocial behavior, and may also stimulate aggression and selfish behavior, with varying effects depending on social context, personality, personal history and gender.

Since 20 years trials have involved clinical groups as well, including patients with autism spectrum disorders, depression, social anxiety, schizophrenia, obsessive-compulsive problems, borderline personality disorder and post-traumatic stress disorder. Although great excitement about the potential role of OT in the treatment of psychiatric disorders can be observed, ${ }^{1-4}$ little is known about its effectiveness as a stand-alone or adjunct pharmacotherapeutic drug. Issues of dosage, timing and side effects in this context have not yet been addressed systematically. Whether OT may serve as a generic anxiolytic drug with positive effects on a large variety of psychiatric disorders ${ }^{5}$ or has more specific effects on a small set of syndromes ${ }^{6}$ is unclear. Here we review and conduct a meta-analysis of OT studies with clinical groups against the background of the scientific evidence on neural and behavioral effects of OT administration in non-clinical groups. We discuss therapeutic potentials as well as limitations of the (adjunct) use of OT in treatment.

\section{Oxytocin}

OT is mainly synthesized in magnocellular neurons of the supraoptic and paraventricular nuclei of the hypothalamus that project to the posterior pituitary. From the pituitary, it is released into the bloodstream to act as a hormone and influence bodily functions. In addition, neurons in the paraventricular nuclei project to various limbic, mid- and hindbrain structures (for example, hippocampus, amygdala and nucleus accumbens) containing a plenitude of OT receptors. Within the brain, OT can act both as a neurotransmitter and as a neuromodulator. ${ }^{7,8}$

Animal studies have shown that OT is involved in lactation and the onset of maternal behavior. ${ }^{9,10}$ Recent research also

Centre for Child and Family Studies, Rommert Casimir Institute for Developmental Psychopathology, Leiden University, Leiden, The Netherlands

Correspondence: MJ Bakermans-Kranenburg or MH van IJzendoorn, Centre for Child and Family Studies, Rommert Casimir Institute for Developmental Psychopathology, Leiden University, PO Box 9555, Leiden 2300 RB, The Netherlands.

E-mail: bakermans@fsw.leidenuniv.nl or vanijzen@fsw.leidenuniv.nl

${ }^{2}$ These two authors contributed equally to this work.

Keywords: autism spectrum disorder; childhood experiences; meta-analysis; oxytocin treatment; psychiatric disorder; randomized controlled trial

Received 11 January 2013; revised 3 March 2013; accepted 15 March 2013 
suggests an important role of OT in human caregiving. ${ }^{11}$ Higher maternal OT levels across pregnancy predict higher quality of postpartum maternal behavior. ${ }^{12}$ In pregnant women, lower plasma OT levels in mid-gestation are predictive of postnatal depression. ${ }^{13}$ More generally, depressive symptomatology has been found related to lower plasma OT levels, ${ }^{14,15}$ although not consistently so. ${ }^{16}$ Similarly, in patients with schizophrenia, plasma OT levels were found to be lower than in non-clinical subjects, and they correlated negatively with psychotic symptoms. ${ }^{17,18}$ Patients with Prader-Willi syndrome were reported to have a deficit in the OT-producing neurons of the paraventricular nuclei. ${ }^{19}$ The idea to use OT administration in the treatment of these clinical groups is thus not far-fetched.

Intranasal OT administration. Early behavioral experiments with intravenous administration of large quantities of OT were short-lived because of disappointing results, ${ }^{20}$ presumably because the blood-brain barrier might have been difficult to pass for OT injected into the veins. Intranasal OT administration seems to circumvent this blood-brain barrier as it leads to replicable changes in brain functioning, $^{21,22}$ perception $^{23}$ and behavior. ${ }^{24}$ Importantly, metaanalytic results show that participants cannot guess whether they received OT or placebo, neither in between-subject nor in within-subject studies, ${ }^{25}$ enabling truly double-blind, placebo-controlled experiments.

The first study on levels of salivary OT after intranasal administration showed that levels remained highly elevated for more than $2 \mathrm{~h}{ }^{26}$ The second study found increased salivary OT levels for the whole 4-h period that assessments took place. ${ }^{27} \mathrm{~A}$ third study followed the participants up to $7 \mathrm{~h}$ after intranasal administration of OT or placebo. ${ }^{28}$ In the placebo condition, salivary OT levels were highly correlated over time, indicating impressive individual stability over the day. At $7 \mathrm{~h}$ after intranasal OT, salivary OT levels were still 6 to 10 -fold higher than those observed in the placebo condition, with 24 and $16 \mathrm{IU}$ showing similar effects. These findings suggest that intranasal OT may be quite effective, also for use in clinical settings.

Intranasal administration of OT is simple to use, but does it reach the receptors in the brain? The nasal mucosa provides a direct connection with the central nervous system, and five absorption routes from the nasal cavity to the central nervous system have been suggested. ${ }^{29}$ These include the transfer of OT through the olfactory epithelium into the systemic circulation, through oral mucosa (after swallowing), through the olfactory bulb pathways directly into the cerebrospinal fluid and brain, through the trigeminal nerve that innervates the respiratory and olfactory epithelium and enters the brain stem and the pons, and through the paravascular spaces that connect into the interstitial spaces of the brain parenchyma. ${ }^{29}$ Not all of these routes have been supported by research with humans, and the identification of markers of response is an important aim for the future, as this will enable specifying and quantifying the impact of the nasal spray. ${ }^{5,6}$

How can the effects of a single OT dose be so protracted that effects can be observed for up to $7 \mathrm{~h}$ ? The feedforward mechanism of the oxytonergic system, leading to an increased production of OT with higher OT levels, may have an important role in the explanation of the persistently high levels after intranasal administration. Treatment with exogenous OT may stimulate a 'feedforward' release of the endogenous peptide, as seen in the Ferguson reflex, in which stimulation of the uterus facilitates the subsequent release of OT. ${ }^{5}$ Nevertheless, basic research on the neurobiological pathway of intranasal OT to pertinent parts of the brain is badly needed.

\section{Experiments with healthy participants}

Anxiolytic promise of OT. During the past 10 years, the number of experiments using intranasal administration of OT to study human perception, emotion, neural reactivity and behavior has increased exponentially. OT sniffs have been found to support empathic concern for conspecifics, ${ }^{8}$ to enhance recognition of emotional facial expressions ${ }^{30-33}$ and to elevate the level of trust in other human beings. ${ }^{34,35}$ One of the first experiments on healthy subjects causing this outburst demonstrated the anxiolytic effect of OT sniffs. ${ }^{36}$ Male students participated in the Trier Social Stress Test, consisting of a public speaking task and mental arithmetic performed in front of an audience. ${ }^{37}$ Half of the students brought their best friend to the lab, whereas the other half came alone. The lowest cortisol reactivity to the stressor was found in the group of students who received OT instead of placebo, and were accompanied by their best friend. Participants who received either social support or OT or both also felt calmer and less anxious during the stress procedure.

This successful experiment triggered a boom of studies, a revival of work carried out in the 1980s and 1990s of the last century, but now with intranasally administered OT.

OT effects on neural activity. The anxiolytic effect of OT found by Heinrichs and co-workers ${ }^{36}$ might be related to reduced amygdala activation. In studies using functional magnetic resonance imaging (fMRI) with healthy male participants, reduced amygdala activation was found in the OT condition when fear-inducing visual stimuli (angry or frightened faces, and fearful or threatening scenes) had to be matched with an identical stimulus. ${ }^{32}$ During placebo, participants showed strong activation of the left amygdala to both types of fear-inducing stimuli, whereas OT decreased amygdala activation, in particular to the faces, and reduced the functional connectivity of the amygdala to the upper brainstem, which mediates arousal and fear behavior. ${ }^{3,38,39}$

Whether OT reduces arousal or downregulates fear may be derived from experiments with positive emotional signals such as infant laughter. Healthy female adults (without offspring) listened in the $\mathrm{fMRI}$ scanner to brief episodes of infant laughter and scrambled control sounds. ${ }^{40}$ OT reduced amygdala activation when individuals listened to infant laughter compared with control sounds. In addition, OT increased functional connectivity between the amygdala and neural reward regions, the orbital frontal cortex and the caudal anterior cingulate cortex. Increased functional connectivity between the orbital frontal cortex, anterior cingulate cortex and amygdala may enhance cognitive control over arousal and at the same time increase the incentive salience of infant laughter. ${ }^{41-45}$ 
A slightly more complicated picture emerged from a study on activation of different subregions of the amygdala to negative and positive stimuli. Participants were instructed to classify briefly presented negative (fearful), positive (happy) or neutral facial expressions as quickly and accurately as possible. ${ }^{46}$ OT decreased activity in lateral and dorsal regions of the anterior amygdala when viewing fearful faces, and stimulated activity in these parts in response to happy faces. OT also increased the proportion of gaze changes toward the eyes across negative as well as positive expressions, and this effect was mediated by enhanced coupling between the posterior amygdala and superior colliculus. OT might thus facilitate the detection of fear or happiness from subtle cues around the eyes.

Female subjects may respond differently to OT administration than male subjects because of sex differences in circulating levels of OT (women tend to have higher levels than men) and because of the regulatory influence of sex hormones, particularly estrogen, on the oxytonergic system. ${ }^{43,47}$ Because the menstrual cycle may influence the effectiveness of OT administration, much more OT studies have been conducted with male than with female participants. The scarce studies on female participants show inconsistent results.

In two studies increased amygdala activation was found in female participants who watched fearful faces ${ }^{48}$ or threatening scenes $^{49}$ after OT administration. However, reduced amygdala activation in response to infant cry sounds has also been observed among female participants. Females twins, without children of their own and in good health, listened to a series of short cry bouts of varying pitch and to scrambled control sounds in the fMRI scanner, either after OT administration or a placebo. ${ }^{22}$ OT administration was related to reduced right amygdala activation and enhanced insula and inferior frontal gyrus activation when exposed to infant crying compared with control sounds. This is particularly relevant since the insula is involved in the perception of the own infant's sad faces ${ }^{50}$ and the inferior frontal gyrus has been associated with empathic prosodic comprehension. ${ }^{51}$ Empathy has been found related to parental responsiveness to infant signals. ${ }^{52-54}$ It is based on a neural simulation mechanism that is activated both when subjected to an emotion and when observing someone else experiencing the emotion, thus enabling humans to understand others' emotions. ${ }^{55,56}$ The insula and inferior frontal gyrus are suggested to have an important role in this simulation process. ${ }^{56-59}$ Decreased amygdala activation might promote responsiveness to infant crying by preventing parents from being overwhelmed by anxious or aversive feelings. This fits well with findings of stress-reducing effects of OT in lactating mothers. ${ }^{60,61}$

Tend and defend. It seems unlikely that OT would be a 'love hormone' or neurotransmitter for prosocial messages in every context. From an evolutionary perspective OT may on the one hand facilitate bonding of the mother to her offspring and release caregiving behavior to nurse-dependent neonates. On the other hand, OT may also enhance the inclination to protect helpless offspring against predators, and thus increase (defensive) aggression against threats from out-group members of the same or other species. ${ }^{9}$

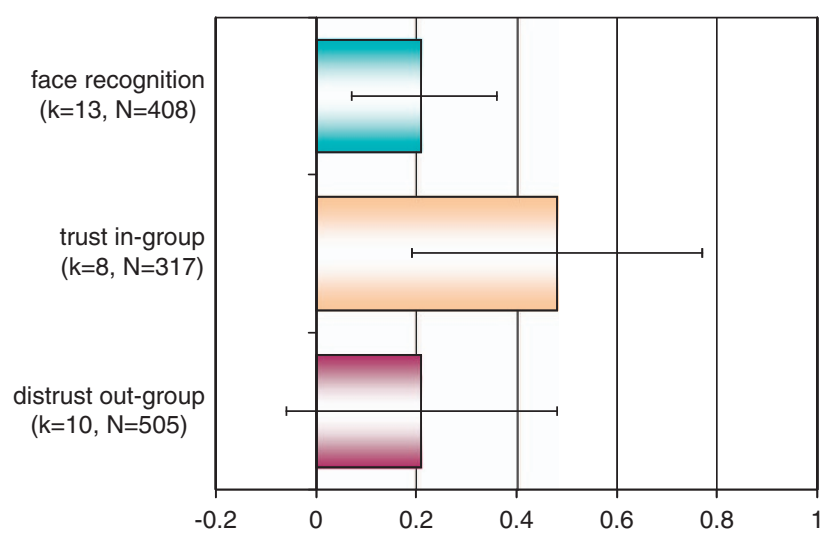

Figure 1 Effects of oxytocin administration on face recognition, trust to in-group and trust to out-group in healthy participants: combined effect sizes (d) and $95 \%$ confidence intervals. The combined effect size for distrust to out-group is not significant.

OT appears to be a double-edged sword that promotes both tending and defending offspring in the service of survival. In a series of experiments with variations of the Prisoners' Dilemma, ${ }^{34}$ OT increased in-group trust but did not affect out-group trust or distrust. These outcomes support and extend previous findings with OT-enhancing trust (only) in the context of social interaction, ${ }^{35}$ and point to the need to take the context into account when establishing the effects of OT administration (Figure 1).

Meta-analytic evidence. Taking stock of the first wave of OT experiments with healthy participants, we tested whether intranasally administered OT leads to more empathic recognition of facial expressions and more trust in conspecifics (see for details Van IJzendoorn and BakermansKranenburg ${ }^{25}$ ). We also examined the hypothesis that OT promotes parochial altruism, suggesting that trust in outgroup members may decrease after OT administration. We identified 23 empirical papers with 31 pertinent effect sizes, providing data for meta-analyses on effects on face recognition (13 effect sizes, $N=408$ ), in-group trust ( 8 effect sizes, $N=317$ ) and out-group distrust (10 effect sizes; $N=505$ ).

Intranasal OT administration was found to enhance the recognition of facial expressions of emotions, and to elevate the level of in-group trust. The experiments conducted to date do, however, not support the hypothesis that out-group distrust is significantly increased in the OT condition. Intranasal OT administration indeed seems 'a sniff of trust', but the effect sizes are more modest than the popular press seems to suggest. The standardized difference between the means of the OT versus placebo condition (Cohen's $d$ ) ranged from weak $(d=0.21$, face recognition) to moderate $(d=0.43$, in-group trust) according to conventional effect size criteria. ${ }^{62}$

This first wave of experiments documents a proof of principle of the perceptual and behavioral effects of intranasal administration of an important neuropeptide involved in social-emotional relationships. It opens a myriad of possibilities to uncover the development and dynamics of emotional empathy and trust in close relationships, and to study the potential effects of OT administration in the treatment of groups with clinical problems in the socioemotional domain. 


\section{Moderation of OT administration effects}

OT is considered to affect skills that are necessary for social interaction, but it does not exert its influence equally to all types of input and all individuals. The context- and persondependent nature of the effects of OT administration has been observed in several reviews. ${ }^{6,25,63}$ Here, we systematically review the moderating effects of context, personality and childhood experiences.

Context. Several studies (and, indeed, our meta-analytic results reported above) point to divergent effects of OT dependent on in-group versus out-group members to whom trust or cooperation is directed. The effect of prior contact is illustrated in a study using the Coordination Game. ${ }^{64}$ Half of the players had brief contact with a group of other players before the game started; with one of them they were matched. The other half were matched with a partner they had not met before the game. OT stimulated cooperative behavior only for those participants who had had brief prior contact with their potential partners, even though they did not know with whom exactly they were matched during the game.

Only a minimum of social cues needs to be present to realize the trust-increasing effect of OT in an economic game. ${ }^{65}$ When trustees were not met in person but described as trustworthy (depicted as studying philosophy, practicing first aid), they were trusted more money than when they were described in a less favorable way (studying marketing, playing violent sports). Larger effects of OT for positive emotions or happy faces compared with angry faces or negative social words ${ }^{66,67}$ may also be considered illustrative of this effect. In a series of studies by De Dreu and co-workers, ${ }^{34}$ OT enhanced in-group trust and cooperation, whereas such positive effects were weaker or absent when the fellow players or recipients were members of out-groups. ${ }^{34}$ Following from the evolutionary idea that OT stimulates parental behavior to protect the own offspring against predators, ${ }^{9}$ it was hypothesized that OT may even increase aggression to out-group members.

Although the supporting evidence for this hypothesis is mixed, two recent studies indicate that differences in outgroup threat matter. In an adapted Prisoner's Dilemma, outgroup threat was manipulated. When it was low, OT had no effect on non-cooperation towards the out-group; when outgroup threat was high, however, participants were significantly more non-cooperative towards the out-group when they had sniffed OT rather than placebo. ${ }^{34}$ In the second study, participants engaged in an intergroup competition and were asked to select allies into their team. ${ }^{68}$ The faces of potential allies were morphed into either high threat (low on trustworthiness and high on dominance) or low threat (high on trustworthiness and low on dominance). Participants in the placebo condition preferred the low-threat allies as teammates, but participants in the OT condition more often selected the high-threat allies as teammates. Under threat of the intergroup competition, OT motivated the selection of allies with high threat potential, presumably to make their in-group appear aggressive rather than friendly.

The (perceived) threat of the 'out-group' may thus have a crucial moderating role: OT administration appears to foster trust and cooperation with individuals that are considered part of the in-group (because they are known, met, or positively described); OT effects are weaker, absent or mixed when the partner is unknown; and OT increases non-cooperation when the partner is perceived as a potential threat. Notably, the perception of others as either a potential threat or a friendly conspecific may be not independent of the individual's social and early caregiving experiences (see below).

Personality. OT provided to individuals with specific deficits in the measure of interest may prove particularly effective. A study on emotion recognition of healthy male subjects varying in social competence is a case in point: ${ }^{30}$ Normal variance in social-cognitive competence moderated the effect of OT. In a within-subject experiment, participants completed a self-report measure of social-cognitive performance $^{69}$ and viewed videos of individuals discussing emotional events. While watching each video, they rated how positive or negative they thought the videotaped individual felt. Participants with high baseline social-cognitive competence performed well on the emotion recognition task in both the placebo condition and in the OT condition, but participants with low baseline social-cognitive competence performed poorly in the placebo condition and no longer fell behind their socially competent peers in the OT condition. Thus, OT improved empathic accuracy only for less socially proficient individuals.

In a related vein, OT increased donations in individuals with greater relative right frontal activity. ${ }^{70}$ The propensity to actively help out or donate money when seeing someone in need may be a natural inclination for individuals with high approach motivation (reflected in greater relative left frontal activity), whereas when approach motivation is low (reflected in less relative left/greater relative right activity), OT enhances empathic concern.

Bartz and co-workers ${ }^{63}$ found that the effects of OT were moderated by participants' attachment style. Although the authors suggest that attachment style $e^{30,71}$ is rooted in early experiences with the caregiver, no empirical data supporting this claim is available; self-reported attachment styles appear to be more closely related to personality characteristics; with anxiety related to the big five personality trait of neuroticism, and avoidance negatively related to extroversion. ${ }^{72-74}$ Nevertheless, the finding that individuals with low scores on attachment anxiety had rosier childhood memories after OT (versus placebo), while individuals with high scores on attachment anxiety remembered their mother as less caring and more distant after OT (versus placebo) is relevant and points to the differentiated effect of OT administration depending on personality characteristics.

Personal history. Developmentally related to the perception of the world as being either a friendly environment or full of threat, childhood experiences may moderate the effect of intranasal OT administration. A growing body of evidence indicates that the prosocial effects of OT administration are stronger for or even limited to individuals with a supportive family background.

In a double-blind, randomized-controlled trial, ${ }^{75}$ we investigated the effects of OT on prosocial behavior during a 
virtual ball-tossing game called Cyberball. ${ }^{76,77}$ Participants were led to believe that they were playing the ball-toss game online with the experimenter and two unknown individuals, and they could throw the ball to the other players using the keyboard. The game consisted of two parts. The first part was fair play with all players receiving one-fourth of the throws. In the second part, however, the experimenter was excluded from the game and did not receive any throws from the two unknown players. We found that participants compensated for other players' ostracism by throwing the ball more often toward the excluded player. OT administration further increased the number of tosses toward the excluded person, but only in individuals who experienced low levels of maternal love withdrawal. The positive effects of OT on prosocial behavior toward a victim of social exclusion were thus limited to individuals with supportive family backgrounds.

In a similar vein, OT increased the participants' willingness to donate money to a charity but only in participants who experienced low levels of parental love-withdrawal. ${ }^{78}$ In a double-blind randomized trial, participants were paid 50 Euros for participation in an ERP (event-related potential) experiment, and then were asked to watch a video while the experimenter cleaned up in the other room. They were shown a 2-min UNICEF promotional film, after which a text appeared on the screen in which the participant was asked to donate money, and a money box had been positioned next to the video screen. Participants in the low love-withdrawal group donated significantly more when they had received OT rather than placebo, but for participants reporting high love-withdrawal, there was no significant difference between the OT and placebo groups in the amount of money donated to UNICEF.

Using a hand-grip dynamometer during listening to infant cry sounds, we tested the effect of intranasal OT administration and experiences with harsh parental discipline during childhood on the use of excessive force in a parenting context. ${ }^{79}$ Participants were twins: one sibling from each twin pair was randomly assigned to the OT condition and the other sibling to the placebo condition, creating well-matched experimental and control groups. Participants were asked to squeeze the handgrip dynamometer as hard as possible and then at $50 \%$ of their maximal handgrip strength. They performed as many trials as necessary for training, with their performance displayed on a monitor to check the $50 \%$ level of each second handgrip, until they were able to modulate the force of their second squeeze to half the strength of their first squeeze. Participants were then requested to squeeze the handgrip dynamometer without receiving feedback eight times at full and half strength, respectively, the first four times listening to infant laughter, and then four times listening to infant crying. Participants' experiences with harsh parental discipline during childhood moderated the effect of OT on the use of excessive force during exposure to infant crying: participants' whose parents did not discipline them harshly used less excessive force in the OT condition, but for participants who were disciplined harshly there was no difference between the OT and placebo condition.

From these studies, it may be concluded that OT administration does not generate positive effects in individuals who as a consequence of unfavorable early caregiving experiences may have a bias towards negative interpretation of social cues. As an alternative or complementary explanation, untoward childhood experiences may interfere with the oxytonergic system on a more fundamental level, for example, affecting neurological pathways or methylation level of the OT receptor (OXTR) gene. In that case differential effects of OT administration should also be visible in a task-free setting.

In an attempt to test the moderating role of caregiving experiences in the absence of social stimuli, we examined the influence of intranasally administered OT on functional brain connectivity with resting state $\mathrm{fMRI}{ }^{80}$ Intranasal OT induced functional connectivity changes between the posterior cingulate cortex (PCC) and the brainstem and, specifically, OTinduced functional connectivity changes between the PCC and the cerebellum and between the PCC and the postcentral gyrus only in participants who experienced low levels of maternal love withdrawal. The PCC is considered a functional connectivity hub because of its high degree of connectivity with other brain regions, ${ }^{81}$ including the thalamus, amygdala, the brainstem, the frontal cortex and the cerebellum. ${ }^{82,83}$ Our finding that intranasal OT changes PCC connectivity is in line with a previous study in which we found that OT increased connectivity between the amygdala and the PCC and other emotional brain regions during exposure to infant laughter. ${ }^{40}$

Increased connectivity between the PCC and the postcentral gyrus suggests that intranasal OT leads to better processing of touch-related information: The postcentral gyrus is part of a somatosensory brain network ${ }^{81}$ that has been associated with the experience of pleasant and human touch. ${ }^{84,85}$ The cerebellum has traditionally been associated with motor function and the coordination of movement. However, recent studies indicate that it also has an important role in emotion and cognition. ${ }^{86,87}$ For example, Alalade et al. ${ }^{88}$ showed that PCC-cerebellum connectivity is altered in patients with depression and suggested that this could represent heightened rumination during resting state. ${ }^{88}$ The cerebellum is one of the least heritable brain structures and is more influenced by environmental factors during development than other brain regions. ${ }^{89}$ Children who experienced early deprivation had smaller superior-posterior cerebellar lobe volumes than a control group. ${ }^{90}$ The susceptibility of the cerebellum to early environmental factors might explain why experiences of love withdrawal moderate OT effects on connectivity between the PCC and the cerebellum, even in a task-free setting.

The moderating effect of adverse childhood experiences was also demonstrated in a pilot study on students. ${ }^{91}$ In a randomized within-subject design, salivary cortisol concentrations were measured before and after double-blind intranasal administration of placebo or OT. About half of the participants had experienced the divorce or permanent separation of their parents before the age of 13 years, with a prolonged separation from one parent as a result. In these participants, cortisol decreases after intranasal OT (versus placebo) were significantly smaller than in participants without early separation experiences, reflecting decreased sensitivity to the effects of intranasal OT.

These studies thus consistently indicate that positive OT effects on behavior or neurobiology are lowered or absent in individuals with negative caregiving experiences. The results 
on resting state connectivity and salivary cortisol levels suggest that quality of caregiving experiences moderates the effects of intranasal OT even in the absence of social stimuli. Early adversity may alter basal oxytonergic system functioning, and likely involves changes at the OT receptor level. Altered receptor density, affinity or function at the OT receptor level may be related to experience-dependent methylation of genetic areas regulating the OT system. Differences in genetic expression may, in turn, lead to decreased sensitivity to intranasal OT.

\section{Experiments with clinical participants}

OT administration has been used in clinical trials with a wide variety of clinical groups, including autism, social anxiety, postnatal depression, obsessive-compulsive problems, schizophrenia, borderline personality disorder and post-traumatic stress. The promise of treating patients with these disorders with OT lies in its anxiolytic role, lowering aversive feelings against potentially disturbing signals such as negative facial expressions or cry sounds, and thus rendering patients less anxious and more at ease with a threatening social environment. Less aversion might lower the threshold for positive interactions despite initially negative social signals.

In general, OT is supposed to facilitate the establishment and maintenance of social relationships. At the same time, the effects of OT administration seem to be dampened in individuals with negative childhood attachment experiences, ${ }^{75,78,79,91}$ which appear to be rather common in many individuals suffering from psychiatric disorders. In this section, we address the question whether OT can improve social functioning and decrease symptomatology of some of the most wide-spread or persistent psychopathologies. We limit our discussion to randomized controlled trials with intravenous or intranasal OT administration. Pertinent studies were found by searching Web of Knowledge and Medline with keywords oxytocin, administration, random*, clinic* and disorder*. References of the studies were screened for additional papers. In addition, references of some recent narrative reviews were screened. ${ }^{2,3,5,8,63}$ The search was completed on 1 November 2012. We found 19 non-overlapping studies, including 304 participants. The findings of these experiments are reviewed below and combined in a meta-analysis to compute the combined effect size across the experiments and to examine whether some psychopathological syndromes are more open to the influence of OT treatment than others.

Autism spectrum disorders. Is OT effective in supporting patients suffering from autism? The effect of OT on repetitive autistic behaviors in 15 adults (14 males) with autism spectrum disorder ( $n=6$ with autism, $n=9$ with Asperger's disorder) was tested using continuous intravenous administration of OT or placebo over a $4-\mathrm{h}$ period. ${ }^{92}$ Six repetitive behaviors were assessed: need to know, repeating, ordering, need to tell/ask, self-injury and touching. The ratings were completed at baseline, and 60, 120, 180 and 240 min after infusion. Although there was no significant main effect for drug, in the OT condition repetitive behaviors (in particular repeating and touching) started to decrease 1 hour after infusion. After $4 \mathrm{~h}, 13$ patients (86.7\%) in the OT condition and only six patients $(40 \%)$ in the placebo condition showed a decrease in repetitive behaviors.

Effects on social cognition of the same trial were also reported. ${ }^{93}$ Comprehension of affective speech was used as outcome measure. Four sentences with neutral content were read aloud with one of four emotional intonations (happy, indifferent, angry and sad), and the participants had to determine the emotional mood expressed. Baseline comprehension and comprehension at 30,60, 120, 180 and 240 min over the course of the infusion was assessed. Compared with subjects who received placebo first, subjects who received OT first showed increased ability to assign accurately emotional meaning to the speech intonations after a delay of about 1 week.

The Reading the Mind in the Eyes Test (RMET) ${ }^{94}$ was used to examine facial emotion recognition in 16 male youth aged 12-19 years with autism or Asperger's disorder with and without OT administration. ${ }^{95}$ The RMET is considered a broad theory of mind assessment involving basic and complex social skills. It tests the ability to infer mood, gender and motor cues from pictures of the eye region of faces. The younger participants (under 15 years) received $18 \mathrm{IU}$ OT or placebo, the older subjects $24 \mathrm{IU}$. The authors found improved performance on the RMET not only in the total group but also in the younger participants with the lower OT dose. The effect seemed strongest for the easier RMET items.

Using an adapted Cyberball computer game, ${ }^{77}$ social decision making was tested in 13 adults ( 11 males) with a clinical diagnosis of Asperger syndrome $(n=10)$ or highfunctioning autism $(n=3) .{ }^{96}$ Participants could throw balls to 'good', 'bad' and 'neutral' players. In the placebo condition, participants did not discriminate between these three players, whereas in the OT condition (24 IU), they threw significantly more balls to the good player compared with the bad player. Patients also reported to trust and to prefer the good player more than the bad player in the OT condition. In the same study, the participants were asked to look at pictures of faces while their eye movements were being recorded, and to report the gender or the gaze direction (direct/averted) of the face. OT decreased the abnormally frequent saccade movements in the patients, and increased fixation time of the informative eye region of the faces on the pictures. Thus, OT made patients with autism more sociable by making them more aware of the social nature of interactions in a computer game, and by supporting them to overcome their reluctance to look faces in the eyes.

Prader-Willi syndrome is a complex genetic disorder with some genetic and phenotypic overlap with autism. ${ }^{97,98}$ Twenty-four Prader-Willi syndrome patients (8 males) were tested with a single dose of 24 IU OT $(n=12)$ or placebo $(n=12) .{ }^{99}$ Patients were observed in their daily routines and scored by trained staff on behavioral scales before and immediately after treatment and during two days following treatment. No immediate effects were found. Patients in the OT group displayed increased trust in others, fewer tendencies towards sadness and less disruptive behavior in the 2 days after intranasal administration. Examining changes from pre- to post-test, however, no significant differences between OT and placebo groups were found. 
Social anxiety disorders. In a study on the effectiveness of group exposure therapy treatment for social anxiety disorder (SAD) in male community patients suffering from SAD OT sniffs were introduced as an adjunct to therapy. ${ }^{1}$ From the second to the last of five weekly sessions, 12 patients received OT (24 IU per session), and 13 subjects received a placebo. At 45 to $90 \mathrm{~min}$ after the administrations, each patient gave a speech in front of group members about increasingly difficult topics. OT reduced the negative mental representations of self, which are typical for SAD patients following a speech exposure task. Participants who received OT showed improvement in their rating of speech appearance, but they did not improve in their ratings of speech performance. There were no immediate or long-term improvements on SAD symptom outcome measures from exposure therapy combined with OT.

In a study using fMRI, the effects of a single intranasal OT administration (24 IU) on neural reactivity to angry and fearful faces in 18 SAD patients and 18 matched healthy controls were examined. ${ }^{100}$ When watching fearful faces, SAD patients showed heightened bilateral amygdala activation compared with controls. OT had no effect on amygdala activity to emotional faces in the control group, but attenuated the heightened amygdala reactivity to fearful faces in the SAD group. In the healthy controls no effect of OT was found. In a subsequent report on the same sample, OT effects on brain activity in response to sad faces compared with neutral facial expressions were reported. ${ }^{101}$ In the SAD group, heightened cortical reactions to sad faces were lowered and normalized after OT. In particular, hyperactivation of the medial prefrontal cortex and the anterior cingulate cortex was downregulated.

Social anxiety is prominent in patients suffering from fragile $X$ syndrome. Administering placebo, $24 \mathrm{IU}$ or $48 \mathrm{IU}$ of OT intranasally at three different occasions 1 week apart social anxiety was measured in eight adolescent or adult male subjects. ${ }^{102}$ The patients were exposed to a social challenge task consisting of $5 \mathrm{~min}$ sitting quietly in a chair close to a female experimenter, after which the experimenter initiated verbal social interaction by asking questions and at the same time prompting the subjects to look them in the eyes. Heart rate and cortisol were measured and mean frequency of participant eye gaze was observed in the social proximity and social interaction phases of the challenge. Eye gaze frequency increased significantly following the $24 \mathrm{IU}$ dose compared with placebo, but not after the $48 \mathrm{IU}$ dose. There was no effect of phase in the challenge. Of the physiological measures, only salivary cortisol levels decreased following $48 \mathrm{IU}$ of OT.

Post-traumatic stress disorder. Twenty years ago Pitman et al. ${ }^{103}$ conducted the first intranasal OT experiment with 43 male Vietnam veterans suffering from post-traumatic stress disorder. Patients received $20 \mathrm{IU}$ OT $(n=15), 20 \mathrm{IU}$ vasopressin $(n=13)$ or placebo $(n=15)$. Heart rate, skin conductance and lateral frontalis electromyographic responses to personal combat imagery were assessed. 'Scripts' portraying subjects' personal events were read to them and subjects were instructed to imagine the events the scripts portrayed. Vasopressin facilitated electromyographic responses to the personal combat imagery, but OT did not have an effect on any of the outcome assessments.

The lack of OT effects on PTSD symptoms in this pioneering study might have blocked the way for further research on OT as a stand-alone treatment or an adjunct to other therapeutic PTSD treatments. Feldman suggested that in her lab data pointing to positive effects of OT on emotional functioning and well-being in combat-related PTSD are emerging. ${ }^{4}$ Whether this promise will be fulfilled in the complete sample is yet to be reported.

In another study on 18 PTSD patients, significant effects of a single dose of 24 IU on PTSD symptoms (measured with the PTSD Symptoms Scale) and on desire for social interaction were found. ${ }^{104}$ The brief report did not present detailed data on sample characteristics or outcome statistics, but it was concluded that OT significantly lowered the intensity of recurrent thoughts about the traumatic event. Mood was elevated and feelings of anxiety reduced.

Depression. In a study on 10 unmedicated female outpatients suffering from major depression and 10 matched healthy controls, the neural reactivity to the $\mathrm{RMET}^{68}$ was examined. ${ }^{105}$ OT (40 IU) increased neural activity during the RMET primarily in emotional circuits such as the cingulate and insula in depressed patients, in particular when patients had to identify mood of the facial expressions. In the OT condition, reaction times decreased for the healthy controls, but they increased in the depressed group. Accuracy of response during the RMET did not change under the influence of OT compared with placebo.

Postnatal depression is rather common and negatively affects the mother-baby relationship. Mah et al. ${ }^{106}$ hypothesized that intranasal administration of OT to mothers with postnatal depression would influence their parenting-related expressed emotion, creating a better basis for sensitive parenting. Twenty-five depressed mothers attending an outpatient perinatal psychiatry setting participated with their young infant. They received $24 \mathrm{IU}$ intranasal OT alternating with placebo approximately 1 week apart. The outcome measures were the Five-Minute Speech Sample used to establish rates of criticism and emotional over-involvement, and the Self-Assessment Manikin for current mood. In the OT condition mothers were sadder, and they more often initially described their babies as difficult. They did not express more emotional overinvolvement or criticism, but they reported that the quality of their relationship with their infant was better. Thus, OT improved mothers' perception of the relationship with their baby, though it did not make them less depressed.

Schizophrenia. Animal studies have shown antipsychotic effects of OT. ${ }^{107}$ In 15 patients (12 males) who received regular antipsychotic medication, the effect of adjunct daily doses of OT (40IU maximum) during 3 weeks was examined. ${ }^{108}$ Unaware raters applied the Positive and Negative Symptom Scale (PANSS) and the Clinical Global Impression-Improvement Scale at each visit. A priori aim was improvement on the total PANSS score at the final visit. PANSS scores showed significant more improvement in the OT compared with placebo condition. The PANSS Clinical 
Global Impression-Improvement Scale showed a similar positive effect. Assessments at prior visits did not reveal improvement. Thus, at least 3 weeks of OT treatment may be needed to create effects on schizophrenic symptomatology. To test amnestic side effects of OT treatment, two cognitive tests were applied: the California Verbal Learning Test and the Letter Number Sequence. ${ }^{109}$ Tests were performed at baseline and after 3 weeks of treatment. No evidence for an amnestic effect was found. In the OT condition, patients showed even better performance on two subtests.

Another study on the antipsychotic effects of OT sniffs included 20 patients (17 males) with a diagnosis of paranoid or undifferentiated schizophrenia who were on standard antipsychotic medication. ${ }^{110}$ Patients received $24 \mathrm{IU}$ OT or placebo two times daily for 14 days. Outcome measures of psychotic symptoms were the PANSS and a Paranoia Scale. Social cognitions were measured with the Brüne Theory of Mind Picture Stories Task and a Trustworthiness Task. Controlling for pretest differences, the OT group showed a significant decline in PANSS, but no effect on social cognition.

Averbeck and co-workers ${ }^{111}$ examined the effects of $24 \mathrm{IU}$ OT on emotion recognition (happiness, surprise, fear, sadness, disgust and anger) in 21 male schizophrenic patients who were on medication with regular antipsychotics. Placebo and OT sessions were 1 week apart. Both morphed and unmorphed faces were displayed and patients indicated which word represented the expressed emotion best. A main effect for OT was found, indicating improved emotion recognition independent of type of emotion and morphing status.

Similar facial emotion expressions were used in a study on 13 schizophrenic patients (seven males) with $(n=5)$ or without $(n=8)$ polydipsia. $^{112}$ Patients received 10 or $20 \mathrm{IU}$ OT or placebo on three occasions. All patients were on regular antipsychotic medication. A conservative estimate of the $20 \mathrm{IU}$ OT effects (compared with placebo) in both polydipsic and non-polydipsic patients on correctly identified emotions amounted to zero. We suggest that their pilot study demonstrated an overall negative impact of 10 IU OT on patients' basal deficits in emotion recognition, while $20 \mathrm{IU}$ ameliorated deficits in the polydipsic but not in the non-polydipsic group. Statistical comparisons with a healthy control group complicate comparisons with OT administration studies in other clinical samples.

Obsessive-compulsive disorders. In an early study, Den Boer and Westenberg ${ }^{113}$ tested the frequency of selfreported obsessive or compulsive behaviors (checking, cleaning) of 12 OCD patients (three males) after OT or placebo in a between-subjects design. The authors did not find a reduction of OCD symptoms after OT, and concluded that the dose of $160 \mathrm{IU}$ per day for 6 weeks (7224 IU in total) might have been too low. In a subsequent pilot treatment with two OCD patients, the authors thus used a threefold higher dosage but again without any noticeable effect. On the positive side, no side effects of these high dosages were seen in terms of psychotic symptoms or memory disturbances.

Large OT doses were also used in a study with seven OCD patients (four males) in a within-subjects design. ${ }^{114}$
OC symptoms were assessed with the Yale-Brown Obsessive Compulsive Scale. Five patients received $160 \mathrm{IU}$ per day for 1 week, whereas two patients sniffed 320 IU per day. No effect was seen for either the smaller or the larger dose. OT also remained ineffective in changing anxiety symptoms, memory capacity or depressive symptoms. In a letter to the editor, Epperson et al. ${ }^{115}$ reported on a similar experiment with two patients suffering from a special type of OCD, namely trichotillomania (compulsive hair pulling), but again without any success.

Borderline personality disorder. Patients suffering from borderline personality disorder struggle with unstable social relationships and lack of trust in significant others. It has been suggested that the enhanced trust after OT found in healthy individuals might not be found in BPD patients because of their insecure attachment style. ${ }^{63}$ In a social dilemma game with a confederate, the cooperative and trusting stance towards others was tested in 14 BPD patients (four males), with six patients receiving $40 \mathrm{IU}$ intranasal OT and eight patients receiving placebo. They also completed the Experience in Close Relationship Scale ${ }^{116}$ to assess attachment style. BPD patients scored more than two standard deviations higher on the scales for anxious and avoidant attachment style compared with healthy controls. BPD patients in the OT condition showed significantly less trust and cooperativeness, and in the OT condition anxious attachment was associated with less cooperation and trust. Another report on the same sample ${ }^{117}$ notes a trend toward attenuated stress reactivity as indexed by cortisol and dysphoria ratings in patients with BPD after OT administration compared with placebo.

\section{Meta-analysis}

The findings of the OT administration studies on clinical samples show great variety, from negative and null effects to remarkably positive outcomes. In a research area with diverging results, meta-analysis might be a tool to integrate and analyze this variety. ${ }^{118}$ Meta-analysis yields an overall or combined effect size, and provides a more detailed analysis of experimental effectiveness in subsets of studies related to specific psychiatric syndromes. We conducted a metaanalysis of the 19 randomized experiments discussed in the section above using Comprehensive Meta-analysis. ${ }^{118}$ When more than one pertinent outcome was reported, we chose the outcome with most face validity for the disorder, and in case of multiple outcomes we combined them meta-analytically within the study. In case of (partly) overlapping samples, we included only one study, so that no participant was included more than once in the meta-analytic data set. Table 1 presents some basic data on design features of the experiments.

For each study, an effect size (d) was calculated as the standardized difference between the two pertinent conditions (OT and placebo). Effect sizes indicating a positive relation between OT administration and either decreased symptomatology or increased social competence were given a positive sign. Using Comprehensive Meta-analysis, combined effect sizes were computed for all studies combined, and for the clinical syndromes separately. Significance tests were 
performed through random-effects models, as this approach is considered to be most widely applicable and conservative. ${ }^{118}$ Random-effects models allow for the possibility that there are random differences between studies that are associated with variations in procedures, measures, settings, that go beyond subject-level sampling error and thus point to different study populations. ${ }^{62}$ To test the homogeneity of the overall and specific sets of effect sizes, we computed
Q-statistics. ${ }^{118}$ In addition, we report 95\% confidence intervals (Cls) around the point estimate of each set of effect sizes.

The combined effect size of the 19 randomized experiments with OT administration in clinical samples was $d=0.32$ $(N=304 ; 95 \%$ Cl: $0.18-0.47 ; \quad P<0.01$, random-effects model), in a homogeneous set of outcomes $(Q=19.67$; $P=0.35)$. This indicates a small-to-moderate effect size according to Cohen's ${ }^{119}$ criteria. $^{119}$ The fail-safe number

Table 1 Randomized controlled trials with oxytocin administration in clinical groups

\begin{tabular}{|c|c|c|c|c|c|c|}
\hline Author & Disorder & $\mathrm{N}$ & $\begin{array}{c}\text { Age mean } \\
\text { (years) (range) }\end{array}$ & $\begin{array}{l}\text { Gender } \\
(\% \text { male })\end{array}$ & Outcome & Task or setting \\
\hline Andari et al. ${ }^{96}$ & Autism & 13 & $26(17-39)$ & 85 & Social decision & Cyberball \\
\hline Guastella et al. ${ }^{95}$ & Autism & 16 & $15(12-19)$ & 100 & Emotion recognition & Reading the Mind in the Eyes Test \\
\hline Hollander et al. ${ }^{93}$ & Autism & 15 & $33(19-56)$ & 93 & Emotion recognition & Vocal intonation \\
\hline Tauber et al. ${ }^{99}$ & Prader-Willi & 24 & $29(18-43)$ & 33 & Social behavior & 2-Day observation \\
\hline Guastella et al. ${ }^{1}$ & Anxiety & 25 & $42(25-65)$ & 100 & Social anxiety & Self-report and clinician ratings \\
\hline Hall et al. ${ }^{102}$ & Anxiety & 10 & $21(13-28)$ & 100 & Eye gaze & Social interaction \\
\hline Labuschagne et al. ${ }^{100}$ & Anxiety & 18 & $29(19-55)$ & 100 & Amygdala response & Fearful faces \\
\hline Pitman et al. ${ }^{103}$ & PTSD & 30 & $44(\mathrm{NR})$ & 100 & $\begin{array}{l}\text { (Neuro-)physiological } \\
\text { responses }\end{array}$ & Personal combat imagery \\
\hline Yatzkar and Klein ${ }^{104}$ & PTSD & 18 & NR (NR) & 100 & PTSD symptoms & Self-report \\
\hline Mah et al. ${ }^{106}$ & Depression & 25 & $28(19-38)$ & 0 & Mood & Self-assessment Manikin \\
\hline Pincus et al. ${ }^{105}$ & Depression & 8 & $35(26-60)$ & 0 & Emotion recognition & Reading the Mind in the Eyes Test \\
\hline Averbeck et al. ${ }^{111}$ & Schizophrenia & 21 & 38 (NR) & 100 & Emotion recognition & Hexagon emotion discrimination task \\
\hline Feifel et al. ${ }^{108}$ & Schizophrenia & 15 & 48 (NR) & 80 & Schizophrenic symptoms & $\begin{array}{l}\text { clinical ratings positive and negative } \\
\text { symptom Scale }\end{array}$ \\
\hline Goldman et al. ${ }^{112}$ & Schizophrenia & 13 & $47(\mathrm{NR})$ & 54 & Emotion recognition & Pictures varying in intensity of emotion \\
\hline Pedersen et al. ${ }^{110}$ & Schizophrenia & 20 & $37(18-55)$ & 85 & Schizophrenic symptoms & $\begin{array}{l}\text { Clinical ratings Positive and Negative } \\
\text { Symptom Scale }\end{array}$ \\
\hline $\begin{array}{l}\text { Den Boer and } \\
\text { Westenberg }\end{array}$ & OCD & 12 & 39 (NR) & 25 & $\begin{array}{l}\text { Obsessive/compulsive } \\
\text { behaviors }\end{array}$ & self-report \\
\hline Epperson et al. ${ }^{114}$ & OCD & 7 & $46(\mathrm{NR})$ & 57 & $\begin{array}{l}\text { Obsessive/compulsive } \\
\text { behaviors }\end{array}$ & Clinical rating Y-BOCS \\
\hline Epperson et al. ${ }^{115}$ & OCD & 2 & $31(30-33)$ & 0 & Hair pulling & Self-report \\
\hline Bartz et al. ${ }^{63}$ & BPD & 14 & 35 (NR) & 29 & Trust and cooperation & Assurance game \\
\hline
\end{tabular}

Abbreviations: BPD, borderline personality disorder; OCD, obsessive-compulsive disorder; NR, not reported; PTSD, post-traumatic stress disorder; Y-BCOS, Yale-Brown Obsessive Compulsive Scale.

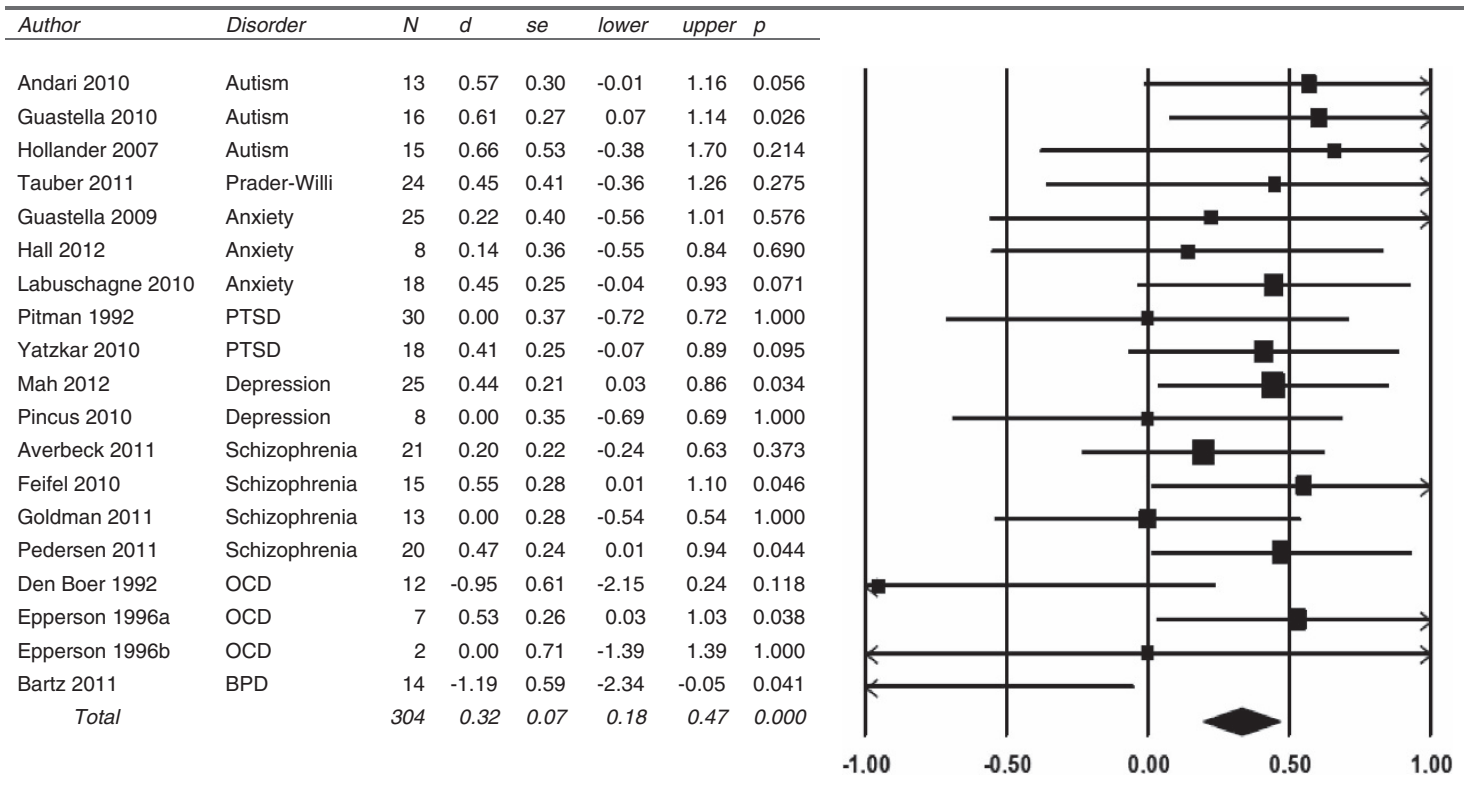

Note. $\mathrm{PTSD}=$ Post Traumatic Stress Disorder $\mathrm{OCD}=$ Obsessive Compulsive Disorder; $\mathrm{BPD}=$ Borderline Personality Disorder

Figure 2 Randomized controlled trials with oxytocin administration in clinical groups: effect sizes (Cohen's $d, 95 \%$ confidence interval) and significance. 
was 52 , that is, 52 studies with null results would be needed to reduce the overall significant result to nonsignificance. This number is smaller than Rosenthal's criterion of $5 k+10$ ( $k=$ the number of studies included in the meta-analysis), indicating that the overall effect size is not very robust. ${ }^{120} \mathrm{We}$ used the 'trim and fill' method ${ }^{121,122}$ to calculate the effect of potential data censoring or publication bias on the outcome of the meta-analyses. Using this method, a funnel plot is constructed of each study's effect size against the sample size or the standard error (usually plotted as 1/s.e., or precision). It is expected that this plot has the shape of a funnel, because studies with smaller sample sizes and larger standard errors have increasingly large variation in estimates of their effect size as random variation becomes increasingly influential, whereas studies with larger sample sizes have smaller variation in effect sizes. ${ }^{122,123}$ The plots would be expected to be shaped like a funnel if no data censoring is present. However, since smaller nonsignificant studies are less likely to be published (the 'file-drawer' problem, ${ }^{124}$ studies in the bottom left hand corner of the plot are often omitted. ${ }^{123}$ With the 'trim and fill' procedure, the $k$ right-most studies considered to be symmetrically unmatched are trimmed and their missing counterparts are imputed or 'filled' as mirror images of the trimmed outcomes. The trim-and-fill approach indicated no publication bias against small studies with small effects in our set of studies.

Controlling for multiple comparisons, only the set of four studies on individuals with autism spectrum disorder (including Prader-Willi syndrome) showed a significant combined effect of $d=0.57(N=68 ; 95 \% \mathrm{Cl}$ : $0.15-0.99 ; P<0.01)$ in a homogeneous set of outcomes $(Q=0.13 ; P=0.99)$. Without the Prader-Willi syndrome study, the combined effect in the remaining set of three autism spectrum disorder studies was still significant $(d=0.60 ; P=0.016)$. Patients diagnosed with other clinical syndromes did not seem to profit from OT administration. It should be noted that the number of studies per syndrome is rather small, and future experimental studies on clinical samples might change this overall somewhat disappointing picture.

\section{Conclusions}

OT research has seen a major upsurge in the past two decades, even though some basic questions have not been answered yet. At a biochemical level, it is still unclear whether peripheral OT levels (in blood, urine or saliva) are correlated with OT levels in the brain, ${ }^{125}$ and there is much debate on whether and how intranasally administered OT reaches the receptors in the brain. ${ }^{5}$ If the pathway causing the behavioral effects of OT treatment is initially peripheral followed by increased central OT levels rather than initially central, then nasal administration is a suboptimal method for increasing central OT levels. ${ }^{29}$ Acknowledging these unsolved puzzles, we conclude that there is sufficient experimental evidence to support the neural and behavioral changes caused by OT sniffs. Despite the black box of the mechanisms through which it penetrates the limbic system and reaches its receptors, it is time to take stock of the evidence from OT studies in normal and clinical groups to explore potentials and limitations of pharmacotherapeutic applications.
In normal groups, the effects of OT appear to be dependent of the (perceived) threat of the 'out-group': OT administration fosters trust and cooperation with individuals that are considered part of the in-group; OT effects are weaker, absent or mixed when the partner is unknown; and OT increases non-cooperation or even aggression when the partner is perceived as a potential threat. OT seems to intensify 'parochial altruism', 34,126 that is, the inclination to defend the in-group against the out-group even when it requires aggression, which from an evolutionary point of view makes sense for the parent of young offspring. Parochial altruism at the group level may be equivalent to protecting offspring even at the expense of the mother's self-interest. ${ }^{127}$

Moreover, recent research indicates that positive OT effects on behavior or neurobiology are lowered or absent in individuals with negative childhood experiences. ${ }^{78,79,91}$ Individual's early caregiving experiences may profoundly affect the cognitive representation and subsequent perception of others as either a potential threat or a friendly conspecific. ${ }^{128,129}$ The results of studies on resting state connectivity $^{80}$ and salivary cortisol levels ${ }^{91}$ suggest that childhood experiences moderate OT effects even in the absence of social stimuli, pointing to environmentally induced changes of the oxytonergic system. We submit that early experiences exert their influence on methylation of genetic areas regulating the oxytonergic system, affecting the system's functioning at the OT receptor level (see Figure 2). Methylation of the receptor gene lowers circulating OT levels and may impede the feedforward mechanism after intranasally administered OT.

It is tempting to suggest that in a similar way differences in experience-dependent methylation may be (partly) responsible for the variation in effectiveness of OT treatment in clinical groups. Only studies on individuals with autism spectrum disorder showed a significant combined effect size $(d=0.57)$, which may reflect the fact that this disorder is mainly genetically determined-except for the pseudoautistic symptoms that can be observed in institutionalized youngsters. ${ }^{130}$ Autism spectrum disorders are to a much lesser extent related to socioemotional experiences than social anxiety, depression or even post-traumatic stress disorder (for which family instability has been identified as an important predictor also in case of combat-related PTSD ${ }^{131,132}$ ). The available evidence seems to indicate that OT may not be capable of easing the latter disorders' often lifetime negative influences on the patients and their families. At the same time, we should note that the database for meta-analytic work is currently modest. For none of the syndromes more than four independent studies were available, and for several of them fewer than four. Sample sizes were small and individual studies did not always show the scientific rigor that is common in OT studies with healthy participants (for example, variation in dose of OT). Moreover, the outcome measures were diverse, ranging from brain activity to symptomatic relief and social competence. More high-quality studies with clinical participants are necessary to consolidate or refute our somewhat disappointing results.

We do not expect that higher dosage of OT will provide a more positive picture for use in clinical groups. Doses up to thousands of IUs have been tried without success. ${ }^{113}$ 


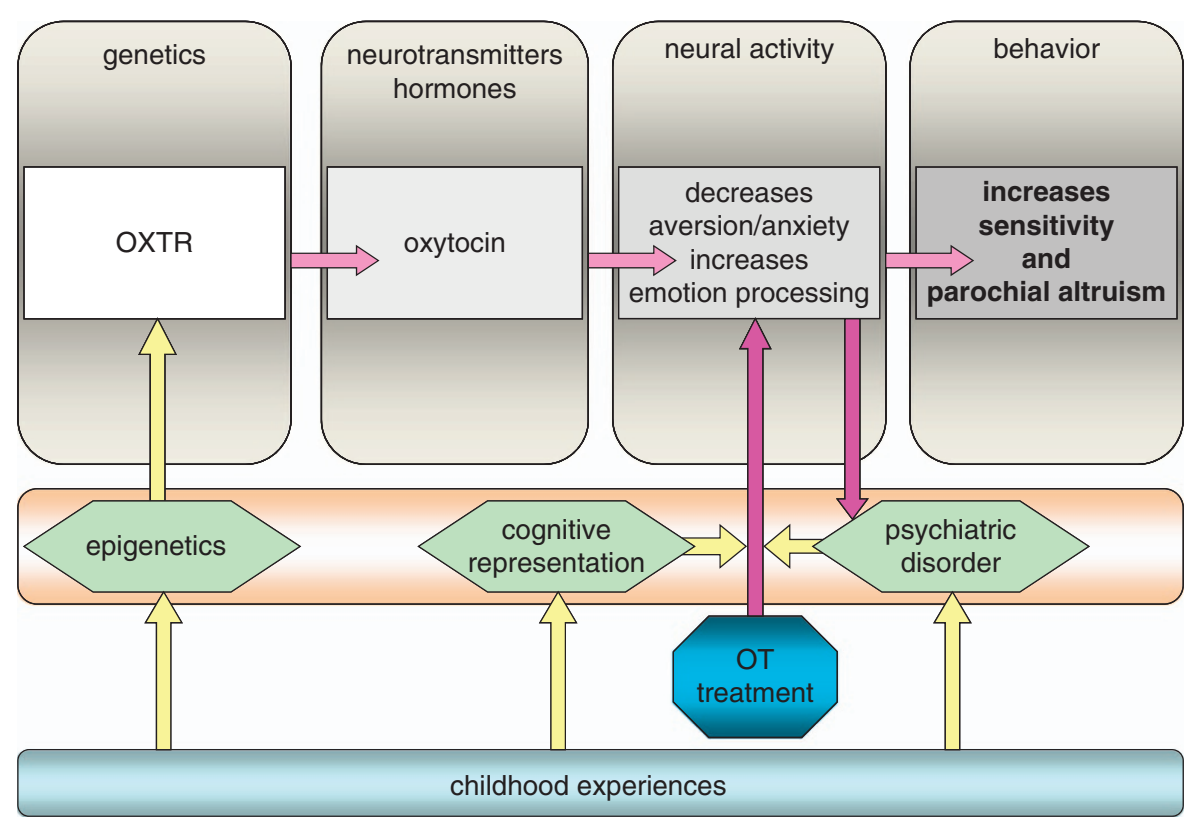

Figure 3 A contextual psychoneurobiological model of oxytocin (OT) treatment: moderation by childhood experiences.

Given that in normal samples much smaller doses have been used in OT experiments in the past 10 years, and that these smaller doses already lead to a 10- to 100-fold increase of salivary OT levels, ${ }^{28}$ it seems overly optimistic to hypothesize that more or stronger sniffs will make the difference. For dosage of OT, it is quite possible that "less is more,28 as an excess of OT might lead to occupation of vasopressin receptors, shifting the balance between OT and vasopressin in the brain. ${ }^{133}$

To the best of our knowledge, only one study examined whether the OT receptor gene (OXTR) moderated the effect of intranasal OT administration. ${ }^{134}$ In a between-subject design, 57 participants of mixed ethnicity viewed infant and adult faces with neutral expressions and they assessed how appealing they found each face. Infant faces were more strongly preferred following OT inhalation relative to placebo, but this effect was only observed for participants homozygous for the rs53576 $\mathrm{G}$ allele. In a similar vein, individuals with one or two copies of the $G$ allele of rs53576 were found to show lower cortisol responses to stress when they received social support compared with a no-support condition, while no such difference was found for $A A$ carriers. ${ }^{135}$ If social support from a partner or close friend can be considered a 'natural' boost of OT, these results may indicate that genetic variation of the oxytonergic system modulates its effectiveness. If so, an individual's genotype (and degree of methylation of the gene) determines what constitutes a sufficient dose to ensure a lasting neural or behavioral effect. This is an important issue for the application of OT administration in clinical practice, not unlike the significance of pharmacogenomics in the treatment of some types of cancer. ${ }^{136}$

In sum, at the moment the pharmacotherapeutic use of OT seems less effective in many psychiatric disorders. We hypothesize that for some of these disorders etiological factors rooted in negative childhood experiences may at the same time have a role in the diminished effectiveness of treatment with OT. On the basis of the trials so far, individuals diagnosed with autism or related disorders seem to profit most from the (adjunct) application of OT, and their socialcommunicative skills might improve significantly. OT is not a generic wonder drug that promotes positive feelings, behaviors and relationships independent of context, personality and personal history. OT may be anxiolytic and may facilitate the establishment and maintenance of (therapeutic) relationships, but adverse personal history may mitigate these potentially beneficial effects.

\section{Conflict of interest}

The authors declare no conflict of interest.

Acknowledgements. We were supported by awards from the Netherlands Organization for Scientific Research (NWO) (MJBK: VICI Grant; MHvIJ: SPINOZA prize).

1. Guastella AJ, Howard AL, Dadds MR, Mtchell P, Carson DS. A randomized controlled trial of intranasal oxytocin as an adjunct to exposure therapy for social anxiety disorder. Psychoneuroendocrinology 2009b; 34: 917-923.

2. Striepens N, Kendrick KM, Maier W, Hurlemann R. Prosocial effects of oxytocin and clinical evidence for its therapeutic potential. Front Neuroendocrinol 2011; 32: 426-450.

3. Yamasue H, Yee JR, Hurlemann R, Rilling JK, Chen FS, Meyer-Lindenberg A et al. Integrative approaches utilizing oxytocin to enhance prosocial behavior: from animal and human social behavior to autistic social dysfunction. J Neurosci 2012; 32: 14109-14117.

4. Feldman R. Oxytocin and social affiliation in humans. Horm Behav 2012; 61: 380-391.

5. Churchland PS, Winkielman P. Modulating social behavior with oxytocin: How does it work? What does it mean? Horm Behav 2012; 61: 392-399.

6. Guastella AJ, MacLeod C. A critical review of the influence of oxytocin nasal spray on social cognition in humans: evidence and future directions. Horm Behav 2012; 61: 410-418.

7. Landgraf R, Neumann ID. Vasopressin and oxytocin release within the brain: a dynamic concept of multiple and variable modes of neuropeptide communication. Front Neuroendocrin 2004; 25: 150-176. 
8. MacDonald K, MacDonald TM. The peptide that binds: a systematic review of oxytocin and its prosocial effects in humans. Harvard Rev Psychiat 2010; 18: 1-21.

9. Carter CS. Neuroendocrine perspectives on social attachment and love. Psychoneuroendocrinology 1998; 23: 779-818.

10. Insel TR. The challenge of translation in social neuroscience: a review of oxytocin, vasopressin, and affiliative behavior. Neuron 2010; 65: 768-779.

11. Galbally M, Lewis A, Van IJzendoorn MH, Permezel M. The role of oxytocin in maternalinfant relationships: a systematic review of human studies. Harvard Rev Psychiat 2011; 19: 1-14.

12. Feldman $R$, Weller $A$, Zagoori-Sharon $O$, Levine A. Evidence for a neuroendrocrinological foundation of human affiliation. Psychol Sci 2007; 18: 965-970.

13. Skrundz M, Bolten M, Nast I, Hellhammer DH, Meinlschmidt G. Plasma oxytocin concentration during pregnancy is associated with development of postpartum depression. Neuropsychopharmacology 2011; 36: 1886-1893.

14. Frasch A, Zetzsche T, Steiger A, Jirikowski GF. Reduction of plasma oxytocin levels in patients suffering from major depression. Adv Exp Med Biol 1995; 395: 257-258.

15. Gordon I, Zagoory-Sharon O, Schneiderman I, Leckman JF, Weller A, Feldman R. 'Oxytocin and cortisol in romantically unattached young adults: associations with bonding and psychological distress'. Dev Psychobiol 2008; 50: 728.

16. Cyranowski JM, Hofkens BA, Frank E, Seltman H, Cai H, Amico J. Evidence of dysregulated peripheral oxytocin release among depressed women. Psychosom Med 2008; 70: 967-975

17. Keri S, Kiss I, Kelemen O. Sharing secrets: oxytocin and trust in schizophrenia. Soc Neurosci 2009; 4: 287-293.

18. Rubin LH, Carter CS, Drogos L, Pournajafi-Nazarloo H, Sweeney JA, Maki PM Peripheral oxytocin is associated with reduced symptom severity inschizophrenia. Schizophr Res 2010; 124: 13-21.

19. Swaab DF, Purba JS, Hofman MA. Alterations in the hypothalamic paraventricular nucleus and its oxytocin neurons (putative satiety cells) in Prader-Willi syndrome: a study of five cases. J Clin Endocrinol Metab 1995; 80: 573-579.

20. Bruins J, Hijman R, Van Ree JM. Effect of a single dose of des-glycinamide[Arg8]vasopressin or oxytocin on cognitive processes in young healthy subjects. Peptides 1992; 13: 461-468

21. Perry A, Bentin S, Shalev I, Israel S, Uzefovsky F, Bar-On D et al. Intranasal oxytocin modulates EEG mu/alpha and beta rhythms during perception of biological motion. Psychoneuroendocrinology 2010; 35: 1446-1453.

22. Riem MME, Bakermans-Kranenburg MJ, Pieper S, Tops M, Boksem MA, Vermeiren RR et al. Oxytocin modulates amygdala, insula, and inferior frontal gyrus responses to infant crying: a randomized controlled trial. Biol Psychiatry 2011; 70: 291-297.

23. Theodoridou A, Rowe AC, Penton-Voak IS, Rogers PJ. Oxytocin and social perception: oxytocin increases perceived facial trustworthiness and attractiveness. Horm Behav 2009; 56: 128-132.

24. Naber F, Van IJzendoorn MH, Deschamps $P$, Van Engeland H, Bakermans-Kranenburg MJ. Intranasal oxytocin increases fathers' observed responsiveness during play with their children: a double-blind within-subject experiment. Psychoneuroendocrinology 2010; 35 : 1583-1586.

25. Van IJzendoorn MH, Bakermans-Kranenburg MJ. A sniff of trust: meta-analysis of the effects of intranasal oxytocin administration on face recognition, trust to in-group, and trust to out-group. Psychoneuroendocrinology 2012; 37: 438-443.

26. Huffmeijer R, Alink LRA, Tops M, Grewen KM, Light KC, Bakermans-Kranenburg MJ et al. Salivary levels of oxytocin remain elevated for more than two hours after intranasal oxytocin administration. Neuroendocrinol Lett 2012; 33: 21-25.

27. Weisman O, Zagoory-Sharon O, Feldman R. Intranasal oxytocin administration is reflected in human saliva. Psychoneuroendocrinology 2012; 37: 1582-1586.

28. Van IJzendoorn MH, Bhandari R, Van der Veen R, Grewen KM, Bakermans-Kranenburg MJ. Elevated salivary levels of oxytocin persist more than $7 \mathrm{~h}$ after intranasal administration. Front Neurosci 2012; 6: 1-6.

29. Guastella AJ, Hickie JB, McGuiness MM, Otis M, Woods EA, Disinger HM et al. Recommendations for the standardization of oxytocin nasal administration and guidelines for its reporting in human research. Psychoneuroendocrinology 2013; 38: 612-625.

30. Bartz JA, Zaki J, Bolger N, Hollander E, Ludwig NN, Kolevzon A et al. Oxytocin selectively improves empathic accuracy. Psychol Sci 2010; 21: 1426-1428.

31. Hurlemann R, Patin A, Onur OA, Cohen MX, Baumgartner T, Metzler $S$ et al. Oxytocin enhances amygdale-dependent, socially reinforces learning and emotional empathy in humans. J Neurosci 2010; 30: 4999-5007.

32. Kirsch $\mathrm{P}$, Esslinger $\mathrm{C}$, Chen Q, Mier D, Lis S, Siddhanti S et al. Oxytocin modulates neural circuitry for social cognition and fear in humans. $J$ Neurosci 2005; 25: 11489-11493.

33. Marsh AA, Yu HH, Pine DS, Blair RJR. Oxytocin improves specific recognition of positive facial expressions. Psychopharmacology 2010; 209: 225-232.

34. De Dreu CKW, Greer LL, Handgraaf MJJ, Shalvi S, Van Kleef GA, Baas M et al. The neuropeptide oxytocin regulates parochial altruism in intergroup conflict among humans. Science 2010; 328: 1408-1411

35. Kosfeld M, Heinrichs M, Zak PJ, Fischbacher U, Fehr E. Oxytocinincreases trust in humans. Nature 2005; 435: 673-676.
36. Heinrichs M, Baumgartner T, Kirschbaum C, Ehlert U. Social support and oxytocin interact to suppress cortisol and subjective responses to psychological stress. Biol Psychiatry 2003; 54: 1389-1398.

37. Kirschbaum C, Pirke KM, Hellhammer DH. The 'Trier Social Stress Test'-a tool for nvestigating psychobiological stress responses in a laboratory setting. Neuropsychobiology 1993; 28: 76-81.

38. LeDoux JE. Emotion circuits in the brain. Annu Rev Neurosci 2000; 23: 155-184.

39. Morrison SE, Salzman CD. Re-valuing the amygdale. Curr Opin Neurobiol 2010; 20: 221-230.

40. Riem MM, van IJzendoorn MH, Tops M, Boksem MA, Rombouts SA, BakermansKranenburg MJ. No laughing matter: intranasal oxytocin administration changes functional brain connectivity during exposure to infant laughter. Neuropsychopharmacology 2012; 37: 1257-1266

41. Berridge KC. The debate over dopamine's role in reward: the case for incentive salience. Psychopharmacology 2007; 191: 391-431.

42. Berridge KC, Kringelbach ML. Affective neuroscience of pleasure: reward in humans and animals. Psychopharmacology 2008; 199: 457-480.

43. Bos PA, Panksepp J, Bluthé RM, Honk JV. Acute effects of steroid hormones and neuropeptides on human social-emotional behavior: A review of single administration studies. Front Neuroendocrinol 2012; 33: 17-35.

44. Haber SN, Knutson B. The reward circuit: Linking primate anatomy and human imaging. Neuropsychopharmacology 2010; 35: 4-26.

45. Kringelbach ML. The human orbitofrontal cortex: linking reward to hedonic experience. Nat Rev Neurosci 2005; 6: 691-702.

46. Gamer M, Zurowski B, Büchel C. Different amygdala subregions mediate valence-related and attentional effects of oxytocin in humans. Natl Acad Sci USA 2010; 107: 9400-9405.

47. Skuse DH, Gallagher L. Dopaminergic-neuropeptide interactions in the social brain. Trends in cognitive sciences 2009; 13: 27-35.

48. Domes G, Lischke A, Berger C, Grossmann A, Hauenstein K, Heinrichs M et al. Effects of intranasal oxytocin on emotional face processing in women. Psychoneuroendocrinology 2010; 35: 83-93.

49. Lischke A, Gamer M, Berger C, Grossmann A, Hauenstein K, Heinrichs M et al. Oxytocin increases amygdala reactivity to threatening scenes in females. Psychoneuroendocrinology 2012; 37: 1431-1438.

50. Strathearn L, Fonagy P, Amico J, Montague PR. Adult attachment predicts maternal brain and oxytocin response to infant cues. Neuropsychofarmacology 2009; 34: 2655-2666.

51. Leitman DI, Wolf DH, Ragland JD, Laukka P, Loughead J, Valdez JN et al. 'It's not what you say, but how you say it': a reciprocal temporo-frontal network for affective prosody. Front Hum Neurosc 2010; 4: 1-13.

52. Gondoli DM, Silverberg SB. Maternal emotional distress and diminished responsiveness: the mediating role of parenting efficacy and parental perspective taking. Dev Psychol 1997; 33: 861-868

53. Leerkes EM. Predictors of maternal sensitivity to infant distress. Parent Sci Pract 2010; 10: 219-239.

54. Feldman R. On the origins of background emotions: From affect synchrony to symbolic expression. Emotion 2007; 7: 601-611.

55. lacoboni M. Imitation, empathy and mirror neurons. Annu Rev Psychol 2009; 60: 653-670.

56. Gallese V, Keysers C, Rizzolatti G. A unifying view of the basis of social cognition. Trends Cogn Sci 2004; 8: 396-403.

57. Chakrabarti B, Bullmore E, Baron-Cohen S. Empathizing with basic emotions: common and discrete neural substrates. Soc Neurosci 2006; 1: 364-384.

58. Decety J, Jackson PL. The functional architecture of human empathy. Behav Cogn Neurosci Rev 2004; 3: 71-100.

59. Jabbi M, Swart M, Keysers $C$. Empathy for positive and negative emotions in the gustatory cortex. Neuroimage 2007; 34: 1744-1753.

60. Heinrichs M, Meinlschmidt G, Neumann I, Wagner S, Kirschbaum C, Ehlert U et al Effects of suckling on hypothalamic-pituitary-adrenal axis responses to psychosocia stress in postpartum lactating women. J Clin Endocrinol Metab 2001; 86: 4798-4804.

61. Heinrichs M, Neumann I, Ehlert U. Lactation and stress: protective effects of breastfeeding in humans. Stress 2002; 5: 195-203.

62. Wilson DB, Lipsey MW. Practical Meta-Analysis. Sage Publications: Newbury Park, CA, USA, 2000.

63. Bartz JA, Zaki J, Bolger N, Ochsner KN. Social effects of oxytocin in humans: context and person matter. Trends Cogn Sci 2011; 15: 301-309.

64. Declerk $\mathrm{CH}$, Boone C, Kiyonari T. Oxytocin and cooperation under conditions of uncertainty: the modulating role of incentives and social information. Horm Behav 2010; 57: 368-374.

65. Micolajczak M, Gross JJ, Lane A, Corneille O, De Timary PH., Luminet O. Oxytocin makes people trusting, not gullible. Psych Sci 2010; 21: 1072-1075.

66. Schulze L, Lischke A, Greif J, Herpertz SC, Heinrichs M, Domes G. Oxytocin increases recognition of masked emotional faces. Psychoneuroendocrinology 2011; 36 1378-1382.

67. Unkelbach C, Graustella AJ, Forgas J. Oxytocin selectively facilitates recognition of positive sex and relationship words. Psychol Sci 2008; 19: 102-104.

68. De Dreu CKW, Greer LL, Shalvi S, Handgraaf MJJ, Van Kleef GA. Oxytocin modulates the selection of allies in intergroup conflict. Proc R Soc Ser B 2012; 279: 1150-1154. 
69. Baron-Cohen S, Wheelwright S, Skinner R, Martin J, Clubley E. The Autism-Spectrum Quotient $(A Q)$ : evidence from Asperger syndrome/high-functioning autism, males and females, scientists and mathematicians. J Autism Dev Disord 2001; 31: 5-17.

70. Huffmeijer R, Alink LRA, Tops M, Bakermans-Kranenburg MJ, Van IJzendoorn MH. Asymmetric frontal brain activity and parental rejection predict altruistic behavior: moderation of oxytocin effects. Cogn Affect Behav Neurosci 2012; 12: 382-392.

71. Fraley RC, Waller NG, Brennan KA. An item-response theory analysis of self-report measures of adult attachment. J Person Soc Psychol 2000; 78: 350-365.

72. Roisman GI, Holland A, Fortuna K, Fraley RC, Clausell E, Clarke A. The adult attachment interview and self-reports of attachment style: an empirical rapprochement. J Person Soc Psychol 2007; 92: 678-697.

73. Noftle EE, Shaver PR. Attachment dimensions and the big five personality traits: associations and comparative ability to predict relationship quality. J Res Person 2006; 40: $179-208$.

74. Van IJzendoorn MH, Bakermans-Kranenburg MJ. Stretched until it snaps: attachment and close relationships. Child Dev Perspect 2010; 4: 109-111.

75. Riem MME, Bakermans-Kranenburg MJ, Huffmeijer R, Van IJzendoorn MH. Does intranasal oxytocin promote prosocial behavior to an excluded fellow player? A randomized controlled trial with Cyberball? Psychoneuroendocrinology 2013 (in press).

76. Crowley MJ, Wu J, McCarty ER, David DH, Bailey CA, Mayes LC. Exclusion and microrejection: event-related potential response predicts mitigated distress. NeuroReport 2009; 20: 1518-1522.

77. Williams KD, Jarvis B. Cyberball: a program for use in research on ostracism and interpersonal acceptance. Behav Res Methods Instr Comput 2006; 38: 174-180.

78. Van IJzendoorn MH, Huffmeijer R, Alink LRA, Bakermans-Kranenburg MJ, Tops M. The impact of oxytocin administration on charitable donating is moderated by experiences of parental love-withdrawal. Front Psychol 2012; 2: 1-8

79. Bakermans-Kranenburg MJ, Van IJzendoorn MH, Riem MME, Tops M, Alink LRA. Oxytocin decreases handgrip force in reaction to infant crying in females without harsh parenting experiences. Soc Cogn Affect Neurosci 2012; 7: 951-957.

80. Riem MME, Van IJzendoorn MH, Tops M, Boksem M, Rombouts SARB, Bakermans-Kranenburg MJ. Oxytocin effects on complex brain networks are moderated by experiences of maternal love withdrawal. Eur Neuropsychopharmacology 2013 (in press).

81. Tomasi D, Volkow ND. Association between functional connectivity hubs and brain networks. Cereb cortex 2011; 21: 2003-2013.

82. Cavanna AE, Trimble MR. The precuneus: a review of its functional anatomy and behavioural correlates. Brain 2006; 129: 564-583.

83. Krienen FM, Buckner RL. Segregated fronto-cerebellar circuits revealed by intrinsic functional connectivity. Cereb Cortex 2009; 19: 2485-2497.

84. Hua QP, Zeng XZ, Liu JY, Wang JY, Guo JY, Luo F. Dynamic changes in brain activations and functional connectivity during affectively different tactile stimuli. Cell Mol Neurobio 2008; 28: $57-70$

85. McCabe C, Rolls ET, Bilderbeck A, McGlone F. Cognitive influences on the affective representation of touch and the sight of touch in the human brain. Soc Cogn Affect Neurosci 2008; 3: 97-108

86. Schmahmann JD. The role of the cerebellum in cognition and emotion: personal reflections since 1982 on the dysmetria of thought hypothesis, and its historical evolution from theory to therapy. Neuropsychol Rev 2010; 20: 236-260.

87. Stoodley CJ. The cerebellum and cognition: evidence from functional imaging studies. Cerebellum 2012; 11: 352-365

88. Alalade E, Denny K, Potter G, Steffens D, Wang L. Altered cerebellar-cerebral functional connectivity in geriatric depression. PLOS One 2011; 6: e20035.

89. Giedd JN, Schmitt JE, Neale MC. Structural brain magnetic resonance imaging of pediatric twins. Hum Brain Mapp 2007; 28: 474-481.

90. Bauer PM, Hanson JL, Pierson RK, Davidson RJ, Pollak SD. Cerebellar volume and cognitive functioning in children who experienced early deprivation. Biol Psychiatry 2009; 66: $1100-1106$.

91. Meinlschmidt G, Heim C. Sensitivity to intranasal oxytocin in adult men with early parental separation. Biol Psychiatry 2007; 61: 1109-1111.

92. Hollander E, Novotny S, Hanratty M, Yaffe R, DeCaria CM, Aronowitz BR et al. Oxytocin infusion reduces repetitive behaviours in adults with autistic and Asperger's disorders. Neuropsychopharmacology 2003; 28: 193-198.

93. Hollander E, Bartz J, Chaplin W, Phillips A, Sumner J, Soorya L. Oxytocin increases retention of social cognition in autism. Biol Psychiatry 2007; 61: 498-503.

94. Baron-Cohen S, Wheelwright S, Hill J, Raste Y, Plumb I. The 'Reading the Mind in the Eyes' Test, revised version: a study with normal adults, and adults with Asperger's syndrome or high-functioning autism. J Child Psychol Psychiatry 2001; 42: 241-251.

95. Guastella AJ, Einfeld SL, Gray KM, Rinehart NJ, Tonge BJ, Lambert TJ et al. Intranasal oxytocin improves emotion recognition for youth with autism spectrum disorders. Bio Psychiatry 2010; 67: 692-694.

96. Andari E, Duhamel JR, Zalla T, Herbrecht E, Leboyer M, Sirigu A. Promoting social behaviour with oxytocin in high-functioning autism spectrum disorders. Proc Natl Acad Sci USA 2010; 107: 4389-4394.

97. Betancur C. Etiological heterogeneity in autism spectrum disorders: more than 100 genetic and genomic disorders and still counting. Brain Res 2011; 1380: 42-77.
98. Hogart A, Wu D, LaSalle JM, Schanen NC. The comorbidity of autism with the genomic disorders of chromosome 15q11.2-q13. Neurobiol Dis 2010; 38: 181-191.

99. Tauber M, Mantoulan C, Copet P, Jauregui J, Demeer G, Diene $G$ et al. Oxytocin may be useful to increase trust in others and decrease disruptive behaviours in patients with Prader-Willi syndrome: a randomised placebo-controlled trial in 24 patients. J Rare Dis 2011; 6: 47.

100. Labuschagne I, Phan KL, Wood A, Angstadt M, Chua P et al. Oxytocin attenuates amygdala reactivity to fear in generalized social anxiety disorder. Neuropsychopharmacology 2010; 35: 2403-2413.

101. Labuschagne I, Phan KL, Wood A, Angstadt M, Chua P et al. Medial frontal hyperactivity to sad faces in generalized social anxiety disorder and modulation by oxytocin. Int $J$ Neuropsychopharmacol 2012; 15: 883-896.

102. Hall SS, Lightbody AA, McCarthy BE, Parker KJ, Reiss AL. Effects of intranasal oxytocin on social anxiety in males with fragile $\mathrm{X}$ syndrome. Psychoneuroendocrinology 2012; 37 : 509-518.

103. Pitman RK, Orr SP, Lasko NB. Effects of intranasal vasopressin and oxytocinon physiologic responding during personal combat imagery in Vietnam veterans with posttraumatic stress disorders. PsychiatryRes 1993; 48: 107-117.

104. Yatzkar U, Klein E. Intranasal oxytocin in patients with post traumatic stress disorder: a single dose pilot double blind crossover study. Clin Neuropsychopharmacol 2009; 32: S84.

105. Pincus D, Kose S, Arana A, Johnson K, Chua P, Morgan, Borckhardt J et al. Inverse effects of oxytocin on attributing mental activity to others in depressed and healthy subjects: a double-blind placebo controlled FMRI study. Front Psychiatry 2010; 1: 134

106. Mah BL, Van IJzendoorn MH, Smith R, Bakermans-Kranenburg MJ. Oxytocin in postnatally depressed mothers: its influence on mood and expressed emotion. Progr Neuro-Psychopharmacol Biol Psychiatry 2013; 40: 267-272.

107. Caldwell HK, Stephens SL, Young WS. Oxytocin as a natural antipsychotic: a study using oxytocin knockout mice. Mol Psychiatry 2009; 14: 190-196.

108. Feifel D, Macdonald K, Nguyen A et al. Adjunctive intranasal oxytocin reduces symptoms in schizophrenia patients. Biol Psychiatry 2010; 68: 678-680.

109. Feifel D, Macdonald K, Cobb P, Minassian A. Adjunctive intranasal oxytocin improves verbal memory in people with schizophrenia. Schizophr Res 2012; 139 : 207-210.

110. Pedersen CA, Gibson CM, Rau SW, Salimi K, Smedley KL, Casey RL et al. Intranasal oxytocin reduces psychotic symptoms and improves Theory of Mind and social perception in schizophrenia. Schizophr Res 2011; 132: 50-53.

111. Averbeck BB, Bobin T, Evans S, Shergill SS. Emotion recognition and oxytocin in patients with schizophrenia. Psychol Med 2011; 41: 1-8.

112. Goldman MB, Gomes AM, Carter CS, Lee R. Divergent effects of two different doses of intranasal oxytocin on facial affect discrimination in schizophrenic patients with and without polydipsia. Psychopharmacology 2011; 216: 101-110.

113. Den Boer JA, Westenberg HG. Oxytocin in obsessive compulsive disorder. Peptides 1992; 13: 1083-1085.

114. Epperson CN, McDougle CJ, Price LH. Intranasal oxytocin in obsessive-compulsive disorder. Biol Psychiatry 1996; 40: 547-549.

115. Epperson CN, McDougle CJ, Price LH. Intranasal oxytocin in Trichotillomania. Biol Psychiatry 1996; 40: 559-561.

116. Brennan KA, Clark CL, Shaver P. Self-report measures of adult romantic attachment. In: Simpson JA, Rholes WS (eds). Attachment Theory and Close Relationships. Guilford Press: New York, NY, USA, 1998.

117. Simeon D, Bartz J, Hamilton H, Crystal S, Braun A, Ketay S et al. Oxytocin administration attenuates stress reactivity in borderline personality disorder: a pilot study. Psychoneuroendocrinology 2011; 36: 1418-1421.

118. Borenstein M, Hedges LV, Higgins JPT, Rothstein HR. Comprehensive Meta-Analysis, Version 2. Biostat: Englewood, NJ, USA, 2005.

119. Cohen J. Statistical Power Analysis for the Behavioral Sciences. 2nd edn Routledge: London, UK, 1988.

120. Rosenthal R. Meta-Analytic Procedures for Social Research. Sage Publications: Newbury Park, CA, USA, 1991.

121. Duval S, Tweedie R. A nonparametric 'trim and fill' method for accounting for publication bias in meta-analysis. J Am Stat Assoc 2000; 95: 89-98.

122. Duval S, Tweedie R. Trim and fill: a simple funnel-plot-based method of testing and adjusting for publication bias in meta-analysis. Biometrics 2000; 56: 455-463.

123. Sutton AJ, Duval SJ, Tweedie RL, Abrams KR, Jones DR. Empirical assessment of effect of publication bias on meta-analyses. BMJ 2000; 320: 1574-1577.

124. Mullen B. Advanced BASIC Meta-Analysis. Lawrence Erlbaum: Hillsdale, NJ, 1989.

125. Leckman JF. Variations in maternal behavior-oxytocin and reward pathwaysperipheral measures matter?! Neuropsychopharmacology 2011; 36: 2587-2588.

126. Bowles S. Being human: conflict: altruism's midwife. Nature 2008; 456: 326-327.

127. Hrdy SB. Mothers and Others: The Evolutionary Origins of Mutual Understanding. Harvard University Press: Cambridge, MA, USA, 2009.

128. Bowlby J. Attachment and Loss Vol 1 (Basic Books: , USA, 1969/1982.

129. Mikulincer M, Shaver PR. Attachment in adulthood. Structure, Dynamics, and Change. Guilford: New York, NY, USA, 2007. 
130. Bakermans-Kranenburg MJ, Steele $\mathrm{H}$, Zeanah $\mathrm{CH}$, Muhamedrahimov RJ, Vorria $\mathrm{P}$ Dobrova-Krol NA et al. Attachment and emotional development in institutional care: characteristics and catch-up. Monogr Soc Res Child Dev 2011; 76: 62-91.

131. Kulka RA, Schlenger WE, Fairbank JA, Hough RL, Jordan BK, Marmar CR et al. Trauma and the Vietnam War Generation: Report of Findings From the National Vietnam Veterans Readjustment Study. Bruner/Mazel: New York, NY,USA, 1990.

132. King DW, King LA, Foy DW, Gudanowski DM. Prewar factors in combat-related posttraumatic stress disorder: structural equation modeling with a national sample of female and male Vietnam veterans. J Consult Clin Psychol 1996; 64: 520-531.

133. Gimpl G, Fahrenholz F. The oxytocin receptor system: structure, function, and regulation. Physiol Rev 2001; 81: 629-683.

134. Marsh AA, Yu HH, Pine DS, Gorodetsky EK, Goldman D, Blair RJR. The influence of oxytocin administration on responses to infant faces and potential moderation by OXTR genotype. Psychopharmacology 2012; 224: 469-476.
135. Chen FS, Kumsta R, Von Dawans R, Monakhov M, Ebstein RP, Heinrichs M. Common oxytocin receptor gene (OXTR) polymorphism and social support interact to reduce stress in humans. Proc Natl Acad Sci USA 2011; 108 : 19937-19942.

136. Evans WE, McLeod HL. Pharmacogenomics-drug disposition, drug targets and side effects. N Engl J Med 2003; 348: 538-549.

cc)(i) $\odot$ Translational Psychiatry is an open-access journal published by Nature Publishing Group. This work is licensed under a Creative Commons Attribution-NonCommercialNoDerivs 3.0 Unported License. To view a copy of this license, visit http://creativecommons.org/licenses/by-nc-nd/3.0/ 